\title{
Systematic review of transcatheter aortic valve replacement after previous mitral valve surgery
}

\author{
John J. Squiers, MD, ${ }^{\text {a,d }}$ Srinivasa Potluri, MD, William T. Brinkman, MD, ${ }^{\mathrm{c}}$ and J. Michael DiMaio, MD ${ }^{\mathrm{a}, \mathrm{c}}$
} Plano and Dallas, Tex

\footnotetext{
From the ${ }^{\mathrm{a}}$ Baylor Scott \& White Research Institute, Departments of ${ }^{\mathrm{b}}$ Cardiology, and ${ }^{\mathrm{c}}$ Cardiothoracic Surgery, The Heart Hospital Baylor Plano, Plano; and ${ }^{\mathrm{d}}$ Department of General Surgery, Baylor University Medical Center, Dallas, Tex.

Disclosures: Authors have nothing to disclose with regard to commercial support.

Received for publication May 12, 2017; revisions received Aug 11, 2017; accepted for publication Aug 24, 2017; available ahead of print Oct 5, 2017.

Address for reprints: J. Michael DiMaio, MD, Baylor Scott \& White Research Institute, The Heart Hospital Baylor Plano, Plano, TX 75093 (E-mail: jmdimaio@yahoo.com).

J Thorac Cardiovasc Surg 2018;155:63-5

$0022-5223 / \$ 36.00$

Copyright (C) 2017 by The American Association for Thoracic Surgery

https://doi.org/10.1016/j.jtcvs.2017.08.129
}

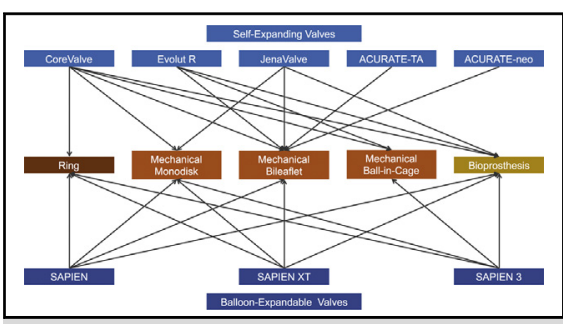

Reported combinations of transcatheter aortic valve replacement valves implanted with previous mitral prostheses

\section{Central Message}

This systematic review suggests that transcatheter aortic valve replacement can be performed safely and successfully in patients with mitral valve prostheses.

See Editorial Commentary page 66.
Only case reports or small case series reporting the outcomes of patients with previous mitral valve (MV) surgery undergoing transcatheter aortic valve replacement (TAVR) are available. ${ }^{1}$ We performed a systematic review to evaluate the feasibility, procedural risks, and outcomes of TAVR in patients with previous MV surgery.

\section{METHODS}

A systematic review of reports of TAVR in patients with previous MV surgery was registered on the PROSPERO database (CRD42017070707) and conducted according to PRISMA (Preferred Reporting Items for Systematic reviews and Meta-Analyses) guidelines. We searched the PubMed/ MEDLINE and EMBASE databases for relevant articles from inception to August 1, 2017. In addition, references from key manuscripts were searched manually in a backward snowballing fashion for additional

erched manually in a backward snowballing fashion for additional

\begin{tabular}{|c|c|c|c|c|c|c|}
\hline & & \multicolumn{5}{|c|}{ Mitral Prosthesis } \\
\hline \multicolumn{2}{|c|}{ TAVR Valve } & Ring & $\begin{array}{l}\text { Mechanical } \\
\text { Monodisk }\end{array}$ & $\begin{array}{l}\text { Mechanical } \\
\text { Bileaflet }\end{array}$ & $\begin{array}{l}\text { Mechanical } \\
\text { Ball-in-Cage }\end{array}$ & Bioprosthesis \\
\hline \multirow{5}{*}{ 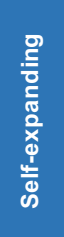 } & CoreValve & 2 & 11 & 13 & 2 & 4 \\
\hline & Evolut R & & & 4 & 1 & 2 \\
\hline & JenaValve & & 1 & 1 & & 1 \\
\hline & ACURATE-TA & & & 1 & & \\
\hline & ACURATE-neo & & & 1 & & \\
\hline \multirow{3}{*}{ 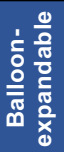 } & SAPIEN & 1 & 3 & 14 & & 6 \\
\hline & SAPIEN XT & 3 & 1 & 11 & & 2 \\
\hline & SAPIEN 3 & 1 & 3 & & 1 & 1 \\
\hline
\end{tabular}

FIGURE 1. All reported combinations of self-expanding and balloon-expandable TAVR valves implanted in the presence of pre-existing mitral prostheses and annuloplasty rings. Only specifically documented combinations are included $(\mathrm{N}=91)$. TAVR, Transcatheter aortic valve replacement. 
TABLE 1. Reported cases of interference between transcatheter aortic valve prosthesis and pre-existing mitral valve prosthesis

\begin{tabular}{|c|c|c|c|}
\hline Study & Acuity & Complication & Outcome \\
\hline Testa and colleagues ${ }^{2}$ & Acute & $\begin{array}{l}\text { Acute, severe MR after CoreValve deployment requiring snaring of } \\
\text { TAVR prosthesis into ascending aorta with resolution of MR }\end{array}$ & Successful repeat TAVR 2 mo later \\
\hline Acar and colleagues ${ }^{3}$ & Acute & $\begin{array}{l}\text { Complete heart block and interference between SAPIEN XT valve } \\
\text { with MV prosthesis; left atrium thrombus; cardiogenic shock }\end{array}$ & Death \\
\hline Squiers and colleagues ${ }^{4}$ & Acute & $\begin{array}{l}\text { Single-tilting disc MV prosthesis impinged by tissue from } \\
\text { aortomitral curtain after post-deployment dilation of SAPIEN } 3 \\
\text { valve; hemodynamic deterioration requiring conversion to SAVR }\end{array}$ & $\begin{array}{l}\text { Discharge home on } \\
\text { postoperative day } 8\end{array}$ \\
\hline Poulin and colleagues $^{5}$ & Chronic & $\begin{array}{l}\text { Six months after TAVR with SAPIEN XT, presents with flail MV } \\
\text { bioprosthesis anterior leaflet causing severe MR and heart failure; } \\
\text { necropsy suggests deformation of MV leaflet due to cyclic contact } \\
\text { with stent edge of the TAVR prosthesis }\end{array}$ & Death \\
\hline
\end{tabular}

$M R$, Mitral regurgitation; TAVR, transcatheter aortic valve replacement; $M V$, mitral valve; $S A V R$, surgical aortic valve replacement.

TAVR. MV replacement was performed in $130(95 \%)$ patients, including $103(75 \%)$ mechanical valves and 27 $(20 \%)$ bioprostheses, and MV repair was performed in 7 (5\%). Aortic annulus to MV prosthesis distance was reported in $48(35 \%)$ patients, with an overall mean of $6.2 \pm 2.9 \mathrm{~mm} ; 6.7 \pm 2.8 \mathrm{~mm}$ for mechanical prostheses, $4.6 \pm 3.3 \mathrm{~mm}$ for bioprostheses, and $4.3 \pm 1.5 \mathrm{~mm}$ for annuloplasty rings.

Approaches were 90 (66\%) transfemoral, 37 (27\%) transapical, $6(4 \%)$ transaortic, $3(2 \%)$ trans-subclavian, and 1 $(<1 \%)$ transcarotid. Both balloon-expandable and selfexpanding TAVR valves were used for a variety of MV prostheses (Figure 1). Complications directly related to the interaction of the TAVR and MV prostheses were reported acutely in $3(2 \%)$ patients and delayed in $1(<1 \%)$ (Table 1$).{ }^{2-5}$ Of 65 patients without a previous pacemaker, $13(20 \%)$ required pacemakers postprocedurally. Paravalvular leak (PVL) was evaluated in all reports and identified in 54 (40\%) patients: grade 1 in $45(34 \%)$; and grade 2 in 9 $(7 \%)$. Two $(1.5 \%)$ patients died before discharge. No significant differences in outcomes, including in-hospital mortality, new pacemaker, and PVL, were identified among TAVR valves, procedural approach, or MV prostheses.

\section{DISCUSSION}

Our systematic review identified 137 reported cases of TAVR after MV surgery. This procedure appears to be feasible and safe for balloon-expandable and selfexpanding TAVR valves with a variety of MV prostheses. However, rare instances of TAVR valve underexpansion and intraventricular prosthesis-prosthesis clash have been reported. These cases were associated with severe complications, including death and conversion to SAVR. ${ }^{3-5}$ In the majority of reported cases, however, no complications related to direct conflict between the TAVR and MV prostheses were documented, and TAVR in patients with previous MV repair was uniformly successful. Given the extreme- to high-risk nature of these patients (median
STS-PROM, 9.9\%), the in-hospital mortality of $1.5 \%$ appeared excellent.

Current "real-world" data from the Transcatheter Valve Therapy (TVT) Registry demonstrates that $11.8 \%$ of TAVR patients require a pacemaker within 30 days. ${ }^{6}$ Therefore, the $20 \%$ rate of new pacemaker implantation in our study may be increased as compared with all patients. The TVT registry does not document echocardiographic data, so the "real-world" rate of PVL after TAVR is difficult to ascertain. In recent prospective trials, moderate or worse PVL has been documented before discharge in $2 \%$ to $3 \%$ of patients. ${ }^{7}$ Given our review encompasses all TAVR valves, we cannot determine whether the increased rate of moderate or worse PVL $(9 \%)$ was primarily due to the presence of MV prostheses or simply a reflection of PVL rates associated with older TAVR valves.

This report is subject to several limitations. We may have missed eligible reports, although we attempted to maximize our search's sensitivity. Although the majority of reported cases document acceptable results, the true incidence of adverse outcomes may be greater, given understandable hesitation to publish poor outcomes and enthusiasm to report positive results. Finally, our review includes many cases in the early era of TAVR. However, no signal was present to suggest that modern TAVR prostheses or the TF approach were associated with different outcomes than earlier generation valves and/or alternative approaches.

In summary, this systematic review of TAVR in patients with previous MV surgery suggests the procedure can be performed safely and successfully. This procedure is associated with increased technical challenges and only should be performed by experienced TAVR implanters. A prospective study or registry is necessary to confirm these findings.

\section{References}

1. Greason KL, Sandhu GS, Nkomo VT, King KS, Joyce DL, Williamson EE, et al. Transcatheter aortic valve insertion after previous mitral valve operation. J Thorac Cardiovasc Surg. 2017; 154:810-5. 
2. Testa L, Gelpi G, Bedogni F. Transcatheter aortic valve implantation in a patient with mechanical mitral prosthesis: a lesson learned from intraventricular clash. Catheter Cardiovasc Interv. 2013;82:E621-5.

3. Acar B, Kuyumcu S, Aydin S, Kara M, Karakurt M, Ozeke O, et al. Fatal prosthetic mitral valve encroachment during transcatheter aortic valve implantation. Int $J$ Cardiol. 2015;182:235-6.

4. Squiers JJ, Hebeler KR, DiMaio JM, Ogbue P, Szerlip M, Brinkman WT. Impingement of a single-tilting disc mitral prosthesis during transcatheter aortic valve replacement. Ann Thorac Surg. 2016;102:e529-31.
5. Poulin F, Lamarch Y, Le VHV, Doucet M, Roméo P, Généreux P. Transcatheter aortic valve replacement in a patient with a previous bioprosthetic mitral valve replacement: report of a delayed fatal interaction. Can J Cardiol. 2016;32:270.e1-2. 6. Grover FL, Vemulapalli S, Carroll JD, Edwards FH, Mack MJ, Thourani VH, et al. 2016 annual report of The Society of Thoracic Surgeons/American College of Cardiology Transcatheter Valve Therapy Registry. J Am Coll Cardiol. 2017;69:1215-30.

7. Thourani VH, Kodali S, Makkar RR, Herrmann CH, Williams M, Babaliaros V, et al. Transcatheter aortic valve replacement versus surgical replacement in intermediate-risk patients: a propensity score analysis. Lancet. 2016;387:2218-25. 


\section{APPENDIX E1}

A systematic review of reports of transcatheter aortic valve replacement (TAVR) in patients with previous mitral valve (MV) surgery was conducted according to PRISMA (Preferred Reporting Items for Systematic reviews and Meta-Analyses) guidelines ${ }^{1}$ and registered in the PROSPERO database (CRD42017070707) (Table E1). We performed a search of the PubMed/MEDLINE and EMBASE databases for relevant articles from inception to August 1, 2017. All articles with the terms \{ "transcatheter aortic valve implantation," "TAVI," "transcatheter aortic valve replacement," OR “TAVR" $\}$ AND \{ "mitral valve," "mitral prosthesis," "mitral replacement," OR "mitral repair" $\}$ located in the title, abstract, or key words were identified to maximize the sensitivity of the search. Additionally, references from key manuscripts were manually searched in a backward snowballing fashion for additional articles.

Included articles had to meet the following criteria: (1) reporting outcomes of TAVR, (2) in human subjects who had previously undergone mitral valve surgery, and (3) written in English. Any peer-reviewed article meeting these criteria, from case reports to randomized control trials, were eligible for inclusion. Exclusion criteria included articles written in a language other than English, reports of concomitant mitral valve surgery and TAVR (ie, a single surgery addressing both valves), or reports regarding a procedure other than TAVR. The resulting list of citations, minus duplicates, was screened at the title/abstract level by a single author (J.J.S.) to identify potentially pertinent studies. At this stage, articles that lacked original data or focused on topics not covered in this review were removed. The full texts of all remaining manuscripts were retrieved for independent assessment by 2 authors (J.J.S., J.M.D.) (Figure E1). Agreement regarding inclusion after full text assessment was $100 \%$ between the independent authors.

Patient-specific data including demographics, MV prosthesis type, interval between MV surgery and TAVR, preoperative risk scores, preoperative imaging results, TAVR characteristics (including valve type, size, and delivery route), TAVR complications (including pacemaker placement, TAVR dysfunction, and MV dysfunction), and inhospital mortality was collected from published reports and tabulated using Excel (Microsoft Corp, Redmond, Wash). Continuous data are reported as mean \pm standard deviation in variables with normal distribution and median \pm interquartile range in non-normally distributed variables. Categorical data are reported as count (percentage). The primary outcomes of interest were in-hospital mortality and TAVR complications. Subgroup analyses stratified by TAVR valve type (self-expanding vs balloonexpanding) and MV prosthesis type (mechanical vs bioprosthesis vs ring) were performed.

On the basis of the preliminary literature review, the authors expected that the risk of bias of included studies was likely to be high, given that the eligible reports included primarily case reports and small case series with the intent to highlight exceptionally good results or specifically to publish bad results as a warning to others. Confidence in the strength of the body of evidence generated by this systematic review was assessed with GRADE criteria, ${ }^{2}$ and given the limited level of evidence available in eligible reports, we assigned a grade of "low quality" (ie, further research is likely to have an important impact on our confidence in the estimate of effect and is likely to change the estimate) to this report. Nevertheless, we planned to proceed with the investigation given the limited data currently available regarding TAVR in patients with previous MV surgery for 2 main reasons: first, to summarize what is currently known about this procedure; and second, to motivate larger prospective study and/or a registry specific to this procedure.

\section{E-References}

E1. Greason KL, Sandhu GS, Nkomo VT, King KS, Joyce DL, Williamson EE, et al. Transcatheter aortic valve insertion after previous mitral valve operation. J Thorac Cardiovasc Surg. 2017;154:810-5.

E2. Rodés-Cabau J, Dumont E, Miró S, Doyle D, De Larochelliére R, Clavel MA, et al. Apical aortic valve implantation in a patient with a mechanical valve prosthesis in mitral position. Circ Cardiovasc Interv. 2008;1:233-5.

E3. Bruschi G, De Marco F, Oreglia J, Colombo P, Fratto P, Lullo F, et al. Percutaneous implantation of CoreValve aortic prostheses in patients with a mechanical mitral valve. Ann Thorac Surg. 2009;88:e50-2.

E4. Dumonteil N, Marcheix B, Berthoumieu P, Massabuau P, Dieye E, Decramer I, et al. Transfemoral aortic valve implantation with pre-existent mechanical mitral prosthesis. JACC Cardiovasc Interv. 2009;2:897-8.

E5. Kahlert P, Eggebrecht H, Thielmann M, Wendt D, Jakob GH, Sack S, et al. Transfemoral aortic valve implantation in a patient with prior mechanical mitral valve replacement. Herz. 2009;34:645-7.

E6. Scherner M, Strauch JT, Haldenwang PL, Baer F, Wahlers T. Successful transapical aortic valve replacement in a patient with a previous mechanical mitral valve replacement. Ann Thorac Surg. 2009;88:1662-3.

E7. Chao VT, Chiam PT, Tan SW. Transcatheter aortic valve implantation with preexisiting mechanical mitral prosthesis - use of CT angiography. J Invasive Cardiol. 2010;22:339-40.

E8. Beller CJ, Bekeredjian R, Krumsdorf U, Leipold R, Katus HA, Karck M, et al. Transcatheter aortic valve implantation after previous mechanical mitral valve replacement: expanding indications? Heart Surg Forum. 2011;14:E166-70.

E9. Bruschi G, De Marco F, Oreglia J, Colombo P, Barosi A, Einaudi A, et al. Transcatheter self-expandable aortic valve implantation after undersized mitral annuloplasty. Ann Thorac Surg. 2011;92:1881-3.

\footnotetext{
${ }^{1}$ Moher D, Shamseer L, Clarke M, Ghersi D, Liberati A, Petticrew M, et al. Preferred reporting items for systematic review and meta-analysis protocols (PRISMA-P) 2015 statement. Syst Rev. 2015;4:1.
}

\footnotetext{
${ }^{2}$ Guyatt GH, Oxman AD, Vist GE, Kunz R, Falck-Ytter Y, Alonso-Coello P, et al. GRADE: an emerging consensus on rating quality of evidence and strength of recommendations. BMJ. 2008;336:924-926.
} 
E10. Drews T, Pasic M, Buz S, Unbehaun A, Dreysse S, Kukucka M, et al. Transapical aortic valve implantation after previous mitral valve surgery. J Thorac Cardiovasc Surg. 2011;142:84-8.

E11. García E, Albarrán A, Heredia-Mantrana J, Guerrero-Pinedo F, Rodríguez J, Hernández-Antolín R, et al. Transcatheter aortic valve implantation in patients with a mechanical mitral valve. Rev Esp Cardiol. 2011;64:1052-5.

E12. Soon JL, Ye J, Lichtenstein SV, Wood D, Webb JG, Cheung A. Transapical transcatheter aortic valve implantation in the presence of a mitral prosthesis. J Am Coll Cardiol. 2011;58:715-21

E13. Barbanti M, Ussia GP, Latib A, De Marco F, Fiorina C, Santoro G, et al. Transcatheter aortic valve implantation in patients with mitral prosthesis. J Am Coll Cardiol. 2012;60:1841-2.

E14. Salinas P, Moreno R, Calvo L, López-Fernández T, Riera L, López-Sendón J. Transfemoral aortic valve implantation in a patient with mitral bioprosthesis: technical features and forethoughts. Rev Esp Cardiol. 2012;65:851-61.

E15. Attia R, Bapat V. Transcatheter aortic valve implantation for treatment of failing homograft with preexisting mechanical mitral prosthesis. Catheter Cardiovasc Interv. 2013;82:324-7.

E16. Bruschi G, De Marco F, Barosi A, Colombo P, Botta L, Nonini S, et al. Selfexpandable transcatheter aortic valve implantation for aortic stenosis after mitral valve surgery. Interact Cardiovasc Thorac Surg. 2013;17:90-5.

E17. Gedikli O, Kutlu M, Civelek A, Ince H. Transcatheter implantation of a CoreValve aortic prosthesis in a patient with a ball-cage mechanical mitral valve. $J$ Heart Valve Dis. 2013;22:697-700.

E18. Rahman MS, Roy D, Brecker SJ. Transcatheter aortic valve implantation in a patient with previous Starr-Edwards mitral valve prosthesis. Heart. 2013;99: 217-8.

E19. Testa L, Gelpi G, Bedogni F. Transcatheter aortic valve implantation in a patient with mechanical mitral prosthesis: a lesson learned from intraventricular clash. Catheter Cardiovasc Interv. 2013;82:E621-5.

E20. Unzué L, García E, Fernández-Friera L, Alegría-Barrero A, Medina-Peralta J, Rodríguez-Rodrigo FJ. Direct transfemoral aortic valve implantation in a patient with a mechanical mitral prosthesis. Rev Esp Cardiol. 2013;66:666-8.

E21. D’Ascenzi F, Iadanza A, Zacá V, Sinicropi G, Torrisi A, Sorropago G, et al How should I treat severe symptomatic aortic stenosis with transcatheter aortic valve implantation in a patient with right aortic arch? Eurointervention. 2014; 10:169-72.

E22. Latsios G, Toutouzas K, Tousoulis D, Synetos A, Stathogiannis K, Mastrokostopoulos A, et al. TAVI with the self-expandable $29 \mathrm{~mm}$ core valve prosthesis in a patient with metallic mitral valve. Int J Cardiol. 2014;175:e4-5.

E23. Minol JP, Veulemanns V, Zeus T, Blehm A. Transcatheter implantation of a newly designed aortic prosthesis in a patient with a mechanical mitral valve. J Thorac Cardiovasc Surg. 2014;148:e202-4.
E24. Vavuranakis M, Vrachatis DA, Kariori MG, Moldovan C, Kalogeras K Lavda M, et al. TAVI in the case of preexisting mitral prosthesis: Tips \& tricks and literature review. J Invasive Cardiol. 2014;26:609-12.

E25. Acar B, Kuyumcu S, Aydin S, Kara M, Karakurt M, Ozeke O, et al. Fatal prosthetic mitral valve encroachment during transcatheter aortic valve implantation. Int J Cardiol. 2015;182:235-6.

E26. Bagur R, Kiaii B, Teefy PJ, Diamantouros P, Harle C, Goela A, et al. Transcatheter ACURATE-TA aortic valve implantation in a patient with previous mechanical mitral valve. Ann Thorac Surg. 2015;100:e115-7.

E27. Daly MJ, Blair PH, Modine T, Donnelly PM, Jeganathan R, Manoharan G, et al Carotic-access transcatheter aortic valve replacement in a patient with a previous mitral valve replacement. J Card Surg. 2015;30:256-9.

E28. O'Sullivan KE, Casserly I, Hurley J. Transapical JenaValve in a patient with mechanical mitral valve prosthesis. Catheter Cardiovasc Interv. 2015;85 916-9.

E29. Sari C, Baştuğ S, Ayhan H, Kasapkara HA, Durmaz T, Keleş T, et al. Transfemoral aortic valve implantation in severe aortic stenosis patients with prior mitral valve prosthesis. Postepy Kardiol Interwencyjnej. 2015;11:304-11.

E30. Sarkar K, Specialie G, Ussia GP. Core valve implant failure in the presence of mechanical mitral prosthesis: importance of assessing left ventricular outflow tract. Catheter Cardiovasc Interv. 2015;85:920-4.

E31. Zacharoulis A, Antoniades A, Frogoudaki A, Kolokathis F, Lekakis J. TAVR in patients with aortic stenosis and mechanical mitral valve. Int J Cardiol. 2015; 180:226-7.

E32. Asil S, Sahiner L, Özer N, Kaya EB, Evranos B, Canpolat U, et al. Transcatheter aortic valve implantation in patients with mitral prosthesis: single center experience and review of literature. Int J Cardiol. 2016;221:390-5.

E33. Maluenda G, Caorsi C, Baeza C. Transfemoral implantation of CoreValve Evolut-R aortic prosthesis in patient with prior ball-cage mechanical mitral valve prosthesis. Cardiovasc Revasc Med. 2016;17:287-9.

E34. Poulin F, Lamarch Y, Le VHV, Doucet M, Roméo P, Généreux P. Transcatheter aortic valve replacement in a patient with a previous bioprosthetic mitral valve replacement: report of a delayed fatal interaction. Can J Cardiol. 2016;32:270 e1-2.

E35. Squiers JJ, Hebeler KR, DiMaio JM, Ogbue P, Szerlip M, Brinkman WT Impingement of a single-tilting disc mitral prosthesis during transcatheter aortic valve replacement. Ann Thorac Surg. 2016;102:e529-31.

E36. Wachter K, Ahad S, Rustenbach CJ, Franke UFW, Baumbach H. Transapical aortic valve implantation in patients with pre-existing mitral valve prostheses: a case report. J Cardiothorac Surg. 2016;11:133.

E37. Bagur R, Pestrichella V, Montesanti R, Alemanni R, Cassese M. Transfemora transcatheter ACURTE-neo aortic valve replacement in a patient with a previous mechanical mitral valve. J Card Surg. 2017;32:358-60. 


\begin{tabular}{|c|c|c|}
\hline $\begin{array}{c}\text { Records identified through } \\
\text { database searching } \\
160\end{array}$ & \multicolumn{1}{|c|}{$\begin{array}{c}\text { Additional records identified } \\
\text { through other sources } \\
12\end{array}$} \\
\hline
\end{tabular}
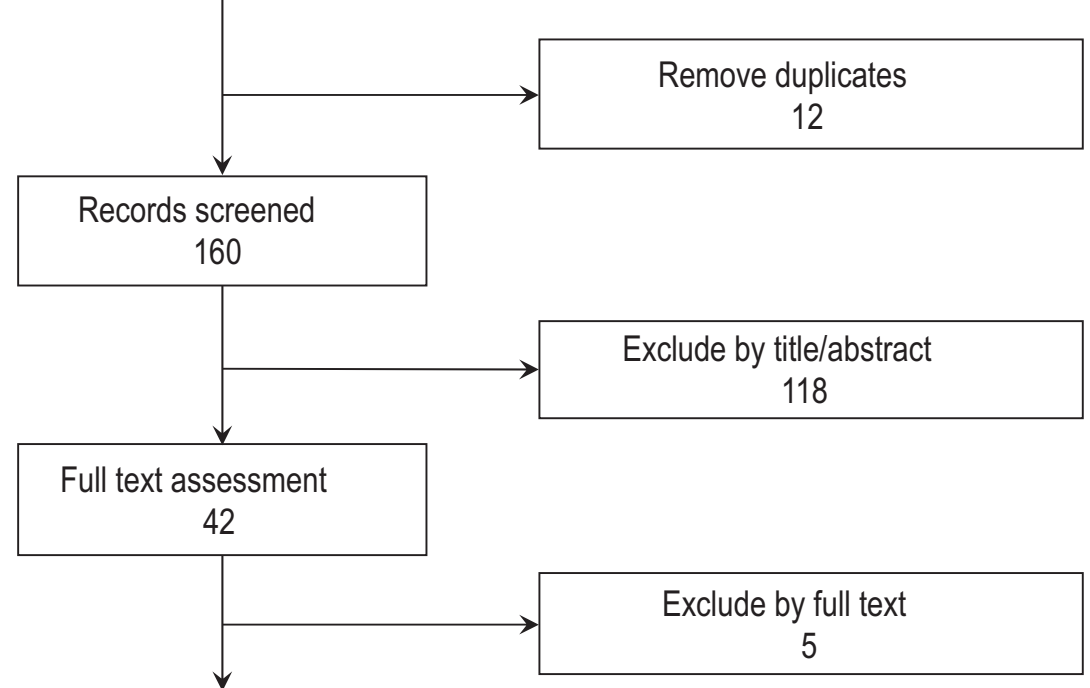

Studies included in qualitative synthesis 37

FIGURE E1. Flow-diagram of the PRISMA (Preferred Reporting Items for Systematic reviews and Meta-Analyses) systematic review process. 


\begin{tabular}{|c|c|c|c|c|c|}
\hline \multirow[b]{2}{*}{ Section/topic } & \multirow[b]{2}{*}{ No. } & \multirow[b]{2}{*}{ Checklist item } & \multicolumn{2}{|c|}{ Information reported } & \multirow[b]{2}{*}{ Line number(s) } \\
\hline & & & Yes & No & \\
\hline \multicolumn{6}{|l|}{ Administrative information } \\
\hline \multicolumn{6}{|l|}{ Title } \\
\hline Identification & $1 \mathrm{a}$ & Identify the report as a protocol of a systematic review & $\mathrm{X}$ & & Main text line 2 \\
\hline Update & $1 b$ & $\begin{array}{l}\text { If the protocol is for an update of a previous systematic } \\
\text { review, identify as such }\end{array}$ & $\mathrm{X}$ & & N/A \\
\hline Registration & 2 & $\begin{array}{l}\text { If registered, provide the name of the registry (eg, } \\
\text { PROSPERO) and registration number in the Abstract }\end{array}$ & $\mathrm{X}$ & & Supplement line 4 \\
\hline \multicolumn{6}{|c|}{ 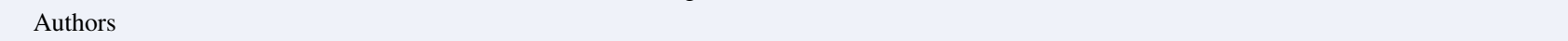 } \\
\hline Contact & $3 a$ & $\begin{array}{l}\text { Provide name, institutional affiliation, and e-mail address of } \\
\text { all protocol authors; provide physical mailing address of } \\
\text { corresponding author }\end{array}$ & $\mathrm{X}$ & & Main text line $4-30$ \\
\hline Contributions & $3 b$ & $\begin{array}{l}\text { Describe contributions of protocol authors and identify the } \\
\text { guarantor of the review }\end{array}$ & $\mathrm{X}$ & & Supplement lines $43-48$ \\
\hline Amendments & 4 & $\begin{array}{l}\text { If the protocol represents an amendment of a previously } \\
\text { completed or published protocol, identify as such and list } \\
\text { changes; otherwise, state plan for documenting important } \\
\text { protocol amendments }\end{array}$ & N/A & N/A & N/A \\
\hline \multicolumn{6}{|l|}{ Support } \\
\hline Sources & $5 \mathrm{a}$ & Indicate sources of financial or other support for the review & $\mathrm{X}$ & & Main text line 35 \\
\hline Sponsor & $5 b$ & Provide name for the review funder and/or sponsor & N/A & N/A & N/A \\
\hline Role of sponsor/funder & $5 \mathrm{c}$ & $\begin{array}{l}\text { Describe roles of funder(s), sponsor(s), and/or institution(s), } \\
\text { if any, in developing the protocol }\end{array}$ & N/A & N/A & N/A \\
\hline \multicolumn{6}{|l|}{ Introduction } \\
\hline Rationale & 6 & $\begin{array}{l}\text { Describe the rationale for the review in the context of what is } \\
\text { already known }\end{array}$ & $\mathrm{X}$ & & Main text lines $52-53$ \\
\hline Objectives & 7 & $\begin{array}{l}\text { Provide an explicit statement of the question(s) the review } \\
\text { will address with reference to PICO }\end{array}$ & $\mathrm{X}$ & & Main text lines 53-54 \\
\hline \multicolumn{6}{|l|}{ Methods } \\
\hline Eligibility criteria & 8 & $\begin{array}{l}\text { Specify the study characteristics (eg, PICO, study design, } \\
\text { setting, time frame) and report characteristics (eg, years } \\
\text { considered, language, publication status) to be used as } \\
\text { criteria for eligibility for the review }\end{array}$ & $\mathrm{X}$ & & Supplement lines 11-21 \\
\hline Information sources & 9 & $\begin{array}{l}\text { Describe all intended information sources (eg, electronic } \\
\text { databases, contact with study authors, trial registers, or } \\
\text { other gray literature sources) with planned dates of } \\
\text { coverage }\end{array}$ & $\mathrm{X}$ & & Supplement lines 11-21 \\
\hline Search strategy & 10 & $\begin{array}{l}\text { Present draft of search strategy to be used for at least one } \\
\text { electronic database, including planned limits, such that it } \\
\text { could be repeated }\end{array}$ & $\mathrm{X}$ & & Supplement lines 4-9 \\
\hline \multicolumn{6}{|l|}{ Study records } \\
\hline Data management & & $\begin{array}{l}\text { Describe the mechanism(s) that will be used to manage } \\
\text { records and data throughout the review }\end{array}$ & $\mathrm{X}$ & & Supplement line 26 \\
\hline Selection process & & $\begin{array}{l}\text { State the process that will be used for selecting studies (eg, } 2 \\
\text { independent reviewers) through each phase of the review } \\
\text { (ie, screening, eligibility, and inclusion in meta-analysis) }\end{array}$ & $\mathrm{X}$ & & Supplement lines 11-21 \\
\hline Data collection process & & $\begin{array}{l}\text { Describe planned method of extracting data from reports (eg, } \\
\text { piloting forms, done independently, in duplicate), any } \\
\text { processes for obtaining and confirming data from } \\
\text { investigators }\end{array}$ & $\mathrm{X}$ & & Supplement lines 22-26 \\
\hline Data items & 12 & $\begin{array}{l}\text { List and define all variables for which data will be sought (eg, } \\
\text { PICO items, funding sources), any pre-planned data } \\
\text { assumptions and simplifications }\end{array}$ & $\mathrm{X}$ & & Supplement lines 22-26 \\
\hline
\end{tabular}


TABLE E1. Continued

\begin{tabular}{|c|c|c|c|c|c|}
\hline \multirow[b]{2}{*}{ Section/topic } & \multirow[b]{2}{*}{ No. } & \multirow[b]{2}{*}{ Checklist item } & \multicolumn{2}{|c|}{ Information reported } & \multirow[b]{2}{*}{ Line number(s) } \\
\hline & & & Yes & No & \\
\hline Outcomes and prioritization & 13 & $\begin{array}{l}\text { List and define all outcomes for which data will be sought, } \\
\text { including prioritization of main and additional outcomes, } \\
\text { with rationale }\end{array}$ & $\mathrm{X}$ & & Supplement lines 29-31 \\
\hline Risk of bias in individual studies & 14 & $\begin{array}{l}\text { Describe anticipated methods for assessing risk of bias of } \\
\text { individual studies, including whether this will be done at } \\
\text { the outcome or study level, or both; state how this } \\
\text { information will be used in data synthesis }\end{array}$ & $\mathrm{X}$ & & Supplement lines $32-42$ \\
\hline \multicolumn{6}{|l|}{ Data } \\
\hline \multirow[t]{4}{*}{ Synthesis } & & $\begin{array}{l}\text { Describe criteria under which study data will be } \\
\text { quantitatively synthesized }\end{array}$ & $\mathrm{X}$ & & Supplement lines $26-28$ \\
\hline & & $\begin{array}{l}\text { If data are appropriate for quantitative synthesis, describe } \\
\text { planned summary measures, methods of handling data, } \\
\text { and methods of combining data from studies, including } \\
\text { any planned exploration of consistency (eg, } I^{2} \text {, Kendall's } \\
\text { tau) }\end{array}$ & $\mathrm{X}$ & & Supplement lines $26-28$ \\
\hline & & $\begin{array}{l}\text { Describe any proposed additional analyses (eg, sensitivity or } \\
\text { subgroup analyses, meta-regression) }\end{array}$ & $\mathrm{X}$ & & Supplement lines 29-31 \\
\hline & & $\begin{array}{l}\text { If quantitative synthesis is not appropriate, describe the type } \\
\text { of summary planned }\end{array}$ & N/A & N/A & N/A \\
\hline Meta-bias(es) & 16 & $\begin{array}{l}\text { Specify any planned assessment of meta-bias(es) (eg, } \\
\text { publication bias across studies, selective reporting within } \\
\text { studies) }\end{array}$ & $\mathrm{X}$ & & Supplement lines $32-42$ \\
\hline Confidence in cumulative evidence & 17 & $\begin{array}{l}\text { Describe how the strength of the body of evidence will be } \\
\text { assessed (eg, GRADE) }\end{array}$ & $\mathrm{X}$ & & Supplement lines $32-42$ \\
\hline
\end{tabular}

PICO, Participants, interventions, comparators, and outcomes. 